\title{
Sprechen Sie Gegenwart? \\ - Um exemplo de léxico da contemporaneidade
}

\section{Masa Nomura*}

Sprechen Sie Gegenwart? - Lexikon des frühen 21. Jahrhunderts. Süddeutsche Zeitung Magazin. Andreas Bernard, Jan HeidtMann, Dominik WiChMAnN (eds.). Editora Goldmann. $1^{a}$. ed. Nov. 2006. No. páginas : 304p. ISBN 19:3-442-15458-8. Preço: € 9,20

\section{O léxico da contemporaneidade}

"Na era da informação instantânea, o futuro vai se insinuando com tal rapidez que o agora está prestes a ser incorporado." (Josias de Souza. "Internauta brasileiro torra 21 horas por mês na net". Folba Online - Blogs - Comentários (30), terça, $23 / 01 / 2007)$

Novas expressões para um mundo novo, expressando novas tendências comportamentais, novos produtos da tecnologia avançada, descobertas científicas de grande impacto; a onipresença da propaganda político-ideológica e da publicidade de consumo no mundo globalizado - toda essa gama complexa de atividades humanas e de acontecimentos do mundo contemporâneo, estampada no noticiário de jornais e revistas, compõe o pano de fundo de Sprechen Sie Gegenwart? Lexikon des frühen 21. Jahrbunderts, léxico lançado em novembro de 2006 na Alemanha, com cerca de 100 verbetes, organizado pela equipe de redatores do conceituado Süddeutsche Zeitung Magazin.

As necessidades criadas para dominar um mundo cada vez mais sofisticado e complexo causaram a rápida obsolescência de uso e o conseqüente desuso de palavras antes correntes e que significavam determinadas coisas em determinados contextos. O domínio absoluto da mídia eletrônica, representada sobretudo pelas redes de televisão, com transmissão em tempo real de seus programas via satélite, e pela rede mundial de internet, possibilitou a meteórica difusão de conceitos novos de várias áreas do conhecimento, de novos modos de pensar e de dizer, de modismos e neologismos, provocando a redefinição do que já existia e

\footnotetext{
* Professora doutora da Área de Alemão do Departamento de Letras Modernas/FFLCH da Universidade de São Paulo.manomura@usp.br
} 
incrementando a criação lexical para nomear e definir coisas antes inexistentes ou desconhecidas.

Billigflieger, betriebsbedingt, Bionade, Blog, CCTV (Closed-Circuit Television), DVBT (Digital Video Broadcasting Terrestrial), durchregieren, durchgecastet, Hörbuch, Klonbaby, metrosexuell, Plasmabildschirm, Podcast, Prekariat, Wikipedia, - são apenas alguns dos muitos neologismos que têm invadido a mídia alemã de forma avassaladora, quer nas programações de redes de TV, quer nas páginas de jornais e revistas e nas páginas da internet. E são essas inovações lexicais que a equipe de redatores do Süddeutsche Zeitung Magaz̧in (SZM) oferece aos leitores em forma de verbetes.

\section{O inovador em Sprechen Sie Gegenwart?}

Um léxico abriga normalmente palavras válidas à época de seu surgimento. O conhecimento nele compilado parece duradouro e confiável, pois toda transformação histórica, passageira, não comprovada ainda, que vem associada aos verbetes, é depurada antes de passar definitivamente para o léxico.

Sprechen Sie Gegenwart? revela já no subtítulo a datação de seus verbetes. Diferente de outras enciclopédias, a historicidade das palavras é levada a sério. Lá estão registrados conceitos familiares antigos, que nos últimos anos sofreram uma transformação básica em seu significado, bem como os neologismos surgidos do nada, que encontraram seu lugar no uso cotidiano. Desse modo, os redatores do SZM fizeram uma seleção de cerca de cem verbetes: conceitos que vieram dos modos de dizer correntes na vida pública e na vida privada. Esses modos de dizer determinaram o tom do noticiário diário, popularizaram o jargão da técnica ou os interesses da cultura, dos esportes e do entretenimento; alguns até se tornaram expressões correntes, outros tiveram seu momento de glória, mas, fora de seu contexto original, tendem a desaparecer, tragados pela fugacidade característica da época contemporânea.

O subtítulo Lexikon des frühen 21. Jahrbunderts é sugestivo: dá a entender que o léxico está apenas começando e que permanece aberto a novos verbetes. Os termos e expressões acolhidos pelo léxico abrangem um leque bastante amplo de tópicos, colhidos ao longo do labor jornalístico. Orienta a seleção de verbetes um propósito definido acoplado a uma determinada ótica jornalística. $\mathrm{Na}$ sua análise, os redatores do SZM não se limitam a explicar apenas os significados de cada verbete, a historiar sua origem e a contextualizar seu uso. Mais do que isso, procuram mostrar o que seu advento e o seu uso têm a dizer sobre o mundo em que vivemos e suas prioridades. 
O livro pode ser lido como o olhar retrospectivo (baseado no ponto de vista da equipe de redatores do SZM) para fatos, acontecimentos, pessoas e objetos da realidade social, todos eles considerados como marcas da contemporaneidade. Cada palavra isoladamente registra algo ou alguém representativo dos primeiros anos do nosso século. Cada palavra funciona como uma espécie de instrução para uso para a época presente, mas sabe-se que, justamente por isso, são palavras que têm prazo de validade. Alguns conceitos, correntes em 2001 e também em 2004, soam agora de forma estranha e provavelmente serão lembrados com muito esforço pela memória humana, já em si seletiva.

\section{Alguns tópicos ilustrativos do novo léxico}

O Brasil presente no léxico alemão

Quem diria que algumas personalidades brasileiras, que em dado momento se celebrizaram graças a uma atividade distinta, ou por gozarem de popularidade junto à mídia internacional, tiveram seu momento de glória e entraram em forma de verbete para o vocabulário alemão? À pág. 168 do léxico, encontramos um exemplo dessa raridade: uma curta biografia de Lula, que vai até as eleições para a presidência da República em outubro de 2006. É dado destaque a certo episódio de seu primeiro governo, ocorrido em 2005, sobejamente conhecido do público brasileiro:

Lula, eigentlich Luiz Inácio Lula da Silva (*Garanhuns/Pernambuco 27.10.1945), gelernter Drechsler, Gewerkschaftsführer, wurde am 27.10.2002 zum brasilianischen Staatspräsidenten gewählt. Bei seinem Amtsantritt galt L. in weiten Teilen der Welt als Hoffnungsträger für eine sozial ausgewogene Politik. Im Sommer 2005 wurde jedoch bekannt, dass zahlreiche Führungskräfte seiner Arbeiterpartei PT in einen der größten Korruptionsskandale Brasiliens verwickelt waren. Auch L. soll von den Vorgängen Kenntnis gehabt haben, nichtsdestotrotz ging er als Favorit in die Präsidentschaftswahlen am 1.10.2006.

Futebol, vocabulário, registro de novos sentidos

É conhecido o amor que o povo alemão devota ao futebol. E o respeito de que gozam na Alemanha os jogadores brasileiros integrantes de seleções vencedoras de campeonatos mundiais. Entretanto, jamais esperaríamos ver citados os nomes de alguns jogadores brasileiros no contexto de uso de um inocente expletivo, que era (ou é) marca registrada de conhecida figura pública alemã! Quem diria que, através do expletivo äh - um cacoete extremamente irritante (para os alemães, obviamente!) do vocabulário ou da falha de memória de um conhecido político bávaro (Edmund Stoiber), seriam citados nomes de futebolistas brasileiros 
como Roberto Carlos, Ronaldo, Ronaldinho, Rivaldo, estrelas que brilharam no firmamento futebolístico da Copa do Mundo de 2002? Pois encontramos essas referências indiretas no verbete äh (pág. 14), cuja definição e contextualização de uso vêm matizadas de fina ironia:

äh, stockendes Element der gesprochenen Sprache, das v.a. vor der Bundestagswahl 2002 ungewöhnlich häufig in Reden und Wortbeiträgen des bayer. Ministerpräsidenten und Unions-Kanzlerkandidakten EDMUND STOIBER $(\rightarrow$ Muschi) zu hören war. Beispielhaft ist Stoibers Kommentar zum Endspiel der Fußball-WM in Südkorea und Japan, gesendet am 1.7.2002 in der ARD: "Vor allen Dingen, wer ein Trio vorne hat wie RONALDO $(\rightarrow$ Passivsex), RONALDINHO und äh, äh, äh „, und äh, die anderen Brasilianer... ROBERTO CARLOS, das ist äh, das ist äh...RIVALDO dazu noch... Rivaldo äh, äh, äh,„, Rivaldo und äh... Ronaldinho und Ronaldo." In den letzten Jahren hat sich Stoibers Gebrauch dieses Füllworts merklich reduziert; Kenner des politischen Lebens mutmaßen daher, dass er nach der in letzter Minute verloren gegangenen Wahl 2002 einen Sprechtrainer engagierte.

A referência que acompanha o nome de Ronaldo nos intriga e desperta nossa curiosidade pelo conteúdo óbvio. À pág. 207, lemos o verbete Passivsex: Nele, porém, não é questionado o comportamento do craque brasileiro, mas é explicada uma prática pouco conhecida do público, destinada a incrementar a produtividade do esportista em campeonatos.

Passivsex, Facette der zwischenmenschlichen Sexualität, die im Lauf der Fußball-Weltmeisterschaft 2002 Bekanntheit erlangte, als der brasilianische Stürmer RONALDO $(\rightarrow$ äh) ihre Bedeutung für die Vorbereitung auf wichtige Spiele betonte. Nach Ronaldos Angaben wird P. zwei Stunden vor Anpfiff einer Partie praktiziert. Der Mann liegt dabei auf dem Rücken und lässt sich, jede körperliche Anstrengung vermeidend, von seiner Partnerin befriedigen. Die Strategie des Ausnahmestürmers steht dabei im Widerspruch zu der oft von Profiboxern vor wichtigen Kämpfen angewandten Methode des Sexverzichts, wovon sich die Kampfsportler eine aggressionssteigernde Wirkung erhoffen.

Zidane e o novo sentido de Kopfstoß

Todo mundo sabe o significado de Kopfsto $\beta$ no sentido estrito, termo comum usado na área esportiva. Um sentido novo foi acrescido ao termo mais recentemente, por ocasião da Copa do Mundo de 2006, quando o atacante Zinedine Zidane, da seleção da França, atingiu com uma potente cabeçada o tórax do zagueiro Marco Materazzi em revide à provocação feita pelo jogador italiano. Às págs. 150-152, o fato é historiado minuciosamente, ilustrado com um desenho baseado na foto que mostra o momento exato em que Zidane aplica o corretivo em Materazzi. 


\section{Nomura, M. - Sprechen Sie Gegenwart? Resenha}

Kopfstoß, Figur aus dem Sport: 1) Billard: senkrechtes Auftreffen des Queue auf den Spielball; 2) Fußball: Spielen des Balles mit dem Kopf, auch: Kopfball; 3) Kampfsport: im klassischen Boxen verbotener Einsatz des Kopfes, in der birmanischen Variante wie auch in der eritreischen Kampfsportart Testa jedoch zulässig. In einer Abwandlung ist der K. seit kurzem besonders unter Kindern und Jugendlichen der frz. Vorstädte $(\rightarrow$ kärchern) populär, seit der frz. Nationalspieler ZINEDINE ZIDANE am 9.7.2006 im Endspiel der FußballWeltmeisterschaft den ital. Abwehrspieler MARCO MATERAZZI mit einem K. auf dessen Brust attackierte. Der folgende Platzverweis für Zidane markierte nicht nur das vorzeitige Ende seiner Karriere als Fußballer, die er mit der Weltmeisterschaft hatte abschließen wollen; der K. legte auch den rüden Umgang der Spieler untereinander offen und zeigte zum Abschluss einer als friedlich beschriebenen Fußball-Meisterschaft, wie dünn der Firnis der Zivilisation dennoch war. - Der K. Zidanes in der 109. Minute der Partie markierte das Ende einer verbalen Auseinandersetzung zwischen beiden Fußballern in der Spielhälfte der Italiener. Nachdem Zidane sich zunächst von Materazzi abgewandt und einige Schritte Richtung Mittellinie gegangen war, drehte er plötzlich um und setzte ankündigungslos zum K. an. Die Tatsache, dass Zidane den K. nicht im Affekt ausführte und damit wohl ein unrühmliches Ende seiner aktiven Karriere akzeptierte, ließ Beobachter sogleich über den Wortlaut der Beleidigung Materazzis spekulieren. Lippenleser des brasilianischen Fernsehsenders Globo kamen zu dem Schluss, dass der italienische Spieler die Schwester Zidanes zweimal als Hure bezeichnet habe, britische Zeitungen mutmaßten, es sei der Satz gefallen: " Alle wissen, dass Du der Sohn einer terroristischen Hure bist." Beide Fußballer weigerten sich in den Wochen nach dem Turnier, den Inhalt der Beleidigung zu offenbaren. Frankreichs Bevölkerung feierte Zidane trotz der Vizemeisterschaft mit den Worten "Zizou, on t'aime" [frz. "Zizou, wir lieben Dich"]. In den folgenden Tagen versuchten sich Schriftsteller, Philosophen und Soziologen in vielerlei Deutungen des K., die von den archaischen Ritualen in der Heimat der Eltern Zidanes, Algerien, bis zu einem "mutigen Akt der Auflehnung" (Javier Marías) reichten. Gleichzeitig thematisierten im Internet zahllose Videofilme und Computerspiele den Hergang des K. - [...]

\section{Neologismos}

Muitas informações complementares de fundo histórico, jornalisticamente documentadas, nos são transmitidas pelo novo léxico. Umas de natureza mais amena, outras mais sérias, e ainda outras, mais restritas ao âmbito da vida cotidiana da Alemanha. Alguns termos só são compreensíveis para os leitores alemães por tratarem de fenômenos tipicamente alemães. Nesse ponto, o léxico da editora Goldmann se revela muito útil, pois ajuda o leitor estrangeiro a decodificar o significado de abreviaturas, siglas etc., que aparecem nos jornais e às quais os leitores alemães certamente estão mais familiarizados, como no caso de aggro (pág. 13-14):

aggro, Kurzform von "aggressiv", gebräuchlich vor allem unter Anhängern des Berliner Hip-Hop-Labels “Aggro Berlin”. In Folge der zumeist positiv besetzten Verwendung des Begriffs in den Liedtexten des Aggro-BerlinRappers SIDO ("Mein Block", "Arschficksong", beide 2004 in der dt. Single- 
Hitparade) gilt a. eher als Bezeichnung einer lebenswerten Eigenschaft, vgl. die Textteile "Wart ihr auch alle schon a.?" (in "Weihnachtssong") oder den Slogan “a. bleiben!”. Im Mittelpunkt der Raptexte Sidos, der sich in der Öffentlichkeit meist mit silberner Totenkopfmaske zeigt, steht die soziale Realität in der Berliner Neubausiedlung Märkisches Viertel.

Celebridades e redefinição de conceitos antigos

O poder da mídia tornou conhecidos do público cidadãos e cidadãs nacionais e internacionais que, ou por obra de algo inusitado que fizeram e/ou disseram, ou pelas artimanhas do marketing pessoal, desfrutaram plenamente dos "cinco minutos de fama", expressão feliz perenizada por Andy Wharhol. Algumas dessas personalidades têm contribuído até para renovar conceitos antigos, que aparentemente nada têm em comum com elas. Sprechen Sie Gegenwart? cita uma delas: Madonna. A cantora pop aparece em dois contextos distintos (verbetes Kabbala, Zungenkuss). O termo Kabbala, prática mística antiga do judaísmo, vem redefinido no léxico em função das circunstâncias que envolveram sua redescoberta pelos seus novos adeptos neste início de século (pág. 134-135):

Kabbala [hebr. "Überlieferung"], die, esoterisch-spekulative Richtung im Judentum, die einem tieferen mystischen Verständnis der Bibel dient. Als erste kabbalistische Schrift gilt das Buch Bahir, entstanden im Südfrankreich des 12. Jh. Die Kabbala wurde im frühen 20. Jh. von dem Religionswissenschaftler GERSCHOM SCHOLEM wiederentdeckt, der frühere Versicherungsagent FEIVEL Gruberger (alias PhILIP BERG) eröffnete in jüngster Zeit rund $25 \mathrm{~K}$.-Zentren in den USA. Zu den bekanntesten K.-Anhängern zählt die Popsängerin MADONNA, die ein circa. neun Mio. Euro teures K.-Zentrum nahe ihrem Londoner Haus finanzierte. Auch BRITNEY SPEARS ( $\rightarrow$ Zungenkuss) begann nach Dreharbeiten mit Madonna, ein rotes K.-Armbändchen ( $\rightarrow$ Livestrong) zu tragen. Auf die Frage eines Journalisten, ob sie sich auch für den Hinduismus interessiere, antwortete Spears: "No, what's that? Is that like Kabbala?" Nach einem Auftritt Madonnas beim jüdischen Purim-Fest im Londoner K.-Zentrum kamen im Frühjahr 2005 jedoch erste Zweifel an der Ernsthaftigkeit ihres Glaubensbekenntnisses auf: Madonna hatte sich als Ordensfrau verkleidet, ihr Mann GuY RiTCHIE als Papst.

Guerra, religião - conotação, alusão

A partir de 11 de setembro de 2001, o mundo já não é mais o mesmo. Esta constatação de que houve uma mudança irreversível nos rumos do mundo, e os episódios tenebrosos que envolveram os Estados Unidos e o Oriente Médio constituíram (e constituem ainda), desde os ataques terroristas comandados pela Al-Qaida a Nova York, em 11.9.2001, matéria jornalística de importância fundamental para toda a humanidade. A partir desse marco histórico, que, de acordo com adeptos de certas crenças religiosas, dividiu maniqueisticamente o mundo em dois eixos, entre o bem e o mal (divisão apregoada sobretudo pelos 
EUA), surgiu na mídia impressa e eletrônica uma série de conceitos, termos e expressões aparentadas com a guerra, que refletem o estado de coisas atual no campo político-ideológico e entraram rapidamente na linguagem corrente; alguns desses exemplos: Achse des Bösen, Al-Qaida, Anthrax, Taliban, Abu Ghraib, Ästhetik des Terrors, Dschibad, Folter, Schläfer, nomes de personalidades e entidades sombrias que representam supostamente o mal (bin Laden, Saddam,Hiabollah) ou o bem (Bush, wiedergeborene Christen).

A propósito de Schläfer, um roedor do tamanho de um rato, um novo significado agregou-se a ele, associado a ativistas do terrorismo islâmico. Essa conotação foi incorporada ao verbete (pág. 235-236):

Schläfer, 1) Familie maus- bis rattengroßer Nagetiere in Eurasien und Afrika, auch unter dem Namen Bilche, Schlafmäuse oder Gliridae bekannt; 2) eingeschleuchte Agenten, die sich im Ausland eine bürgerliche Existenz aufbauen, um auf ein bestimmtes Kommando hin in Aktion zu treten. Die Bez. S. tauchte bereits in der Zeit des kalten Krieges auf. Gebräuchlich wurde sie aber erst nach den Terroranschlägen in New York und Washington am 11.9.2001, als sich herausstellte, dass die Haupttäter als unauffällige Studenten in Dtl. gelebt hatten und die Anschläge mehr als ein Jahr lang unbemerkt vorbereiten konnten. Als S. wurden in der Folge v.a. radikale Muslime bezeichnet, die zumeist eine militärische Ausbildung in Afghanistan absolviert haben, um dann im Ausland auf Abruf für einen Kampfeinsatz bereit zu stehen. Mit der Einführung einer eigens auf S. ausgerichteten Rasterfahndung wurde vom Bundeskriminalamt im Herbst 2001 ein Täterprofil mutmaßlicher S. entwickelt. Als potenzielle Verdachtsmomente galten folgende Mertkmale: Bürger eines arabischen Staates, männlich, kinderlos, angepasst, Student eines techn. Faches, reisefreudig, zudem finanziell unabhändig, da die S. vom Umfeld OSAMA $\rightarrow$ BIN LADENS mit ausreichend Geld versorgt werden. Die Ermittlungen der Polizeibehörden führten jedoch nicht zur Enttarnung weiterer S.; die allzu vagen Kriterien der Rasterfahndung hatten vielmehr zur Folge, dass diese Form der Datenerhebung in den Jahren 2002 und 2003 von den Verwaltungsgerichten mehrerer dt. Bundesländer untersagt wurde.

Quanto a wiedergeborene Christen, que vem associado ao nome do atual presidente dos EUA, a explicação desta alusão à crença religiosa do presidente americano é dada às págs. 293-294:

wiedergeborene Christen, eine in Nordamerika auftretende Gruppe von Anhängern des christlich-protestantischen Glaubens, meistens methodistischer oder baptistischer Prägung. Gemäß dem Johannes Evangelium (Kapitel 3, Verse 3-8), in dem Jesus sagt, "Wundere dich nicht, dass ich dir gesagt habe: Ihr müsst von neuem geboren werden", geben w.C. an, ihren Glauben als Erwachsene durch ein besonderes Bekehrungserlebnis erst gefunden oder gefestigt zu haben. Oft können die w.C. dieses Erlebnis mit Datum und Uhrzeit benennen und daran den Beginn eines neuen Lebens festmachen, das mögliche Verfehlungen in der Zeit vor dem Erweckungserlebnis tilgt. Viele w.C. nehmen in der Folge ein 
fundamentalistisches Glaubensverständnis an, das eine rückwärt gewandte Weltanschauung einschließen kann, und lehnen die Errungenschaften moderner, $\rightarrow$ offener Gesellschaften ab, wie z.B. homosexuelle Partnerschaften $(\rightarrow$ HomoEhe) oder Geschlechtsverkehr vor der Ehe. Schätzungen zufolge bezeichnen sich in den USA 20\% der Christen als wiedergeboren. Prominentester Vertreter dieser Glaubensrichtung ist US-Präsident George W. Bush, der seine Wiederwahl am 2.11.2004 zu nicht geringem Teil den w.C. verdankt. Bush, der formal der gemäßigsten United Methodist Church angehört, glaubt, Gott habe ihm an seinem 40. Geburtstag dabei geholfen, über seinen laxen Lebensstil und sein Alkoholproblem hinwegzukommen. Internationale Beobachter merken indes an, Gott hätte der Welt einen größeren Gefallen getan, hätte er Bush mit seinem Alkoholproblem dort gelassen, wo er war.

Literatur: Die Bibel, Johannes, 3, 3-8.

\section{A contemporaneidade refletida no léxico}

As fontes utilizadas pelo léxico do SZM são, como vimos, as matérias jornalísticas de maior ou menor impacto colhidas das páginas da mídia impressa e eletrônica, a contar dos primeiros anos deste século. Elas narram a história da época contemporânea em fluxo contínuo, dando conta das transformações por que passaram (e passam ainda) as instituições, os costumes, as sociedades, o meio sociocultural e ambiental - enfim, a realidade do mundo em que vivemos. Os relatos, descrições e definições podem ser considerados documentos vivos da história que ainda se desenrola. Como todo discurso jornalístico, não falta ao texto do léxico uma interpretação crítica contundente e um humor sutil infiltrado nas entrelinhas. Esse olhar crítico dá sabor à leitura do texto e constitui por si mesmo uma inovação no que concerne à elaboração de léxicos.

É, portanto, pela perspectiva do jornalismo contemporâneo que o léxico deve ser lido. Os fatos do hic et nunc continuam a sacudir o mundo e imprimem a marca de sua presença transformadora na linguagem que usamos. Essas transformações pedem novas formas de expressão, pois já não podem mais ser cobertas por palavras e conceitos antigos.

Sprechen Sie Gegenwart? é uma contribuição organizada para definir o estado fluido das coisas do nosso tempo. Quem sabe, daqui a alguns poucos anos, os conceitos já se tenham transformado novamente, e personalidades que ficaram em evidência na mídia já tenham caído na obscuridade, e os objetos antes intensamente desejados tenham se tornado obsoletos. E ninguém mais consiga relacionar a palavra ao fato, à pessoa ou ao objeto que a marcou tão fortemente à época de seu surgimento. 